\title{
REENCANTAMIENTO SOCIAL CON EL PATRIMONIO BIOCULTURAL MEDIANTE UNA ESTRATEGIA DE DISEÑO PARA LA INNOVACIÓN SOCIAL. ESTUDIO DE CASO: CREATIVIDAD INFANTIL
}

\section{Entorno Cultura}

Hellen Yurani Zamudio Ceballos

hellenzamudio@gmail.com

Universidad de Caldas.

Manizales, Caldas.

Diseño social,

innovación social,

Palabras Clave: memoria cognitiva, patrimonio biocultural, reencantamiento. 


\section{Resumen}

El artículo describe la investigación a través del diseño para salvaguardar el patrimonio — biocultural nariñense, mediante una estrategia de diseño para la innovación social. Esto debido a que la sociedad actual está abandonando el aprendizaje de la expresión gráfica de la cultura Quillacinga tradicional, distanciándose del conocimiento simbólico ancestral. La investigación, desde el enfoque etnográfico, se basó en la acción-participativa con los niños del grado quinto de la Institución Educativa Municipal de El Encano, sede El Puerto, en la laguna de La Cocha (Departamento de Nariño), en un periodo de cinco años (20122016). Se implementaron las técnicas cualitativas de análisis e interpretación: documentos bibliográficos, fuentes museológicas, entrevistas semi-estructuradas, taller de dibujo creativo, preguntas y la antropología visual. El estudio reveló que la aves acuáticas, representadas simbólicamente en el sistema (artefacto) plástico-sensorial con las narraciones digitales en el cuento interactivo, generan esas experiencias para lograr reencantar socialmente, al perdurar los conocimientos a través del tiempo en la memoria cognitiva.

\section{Introducción}

El reencantamiento social desde el patrimonio biocultural se ha convertido en una nueva problemática para abordar e intervenir a través del diseño como sujeto y objeto de investigación, para generar conocimiento entre práctica y teoría (Herrera, 2010). Esto tiene mucha relación por cuanto estas dos se complementan con la validación de la epistemología del diseño y la implementación teórica- metodológica-práctica para la investigación acciónparticipativa, como una filosofía de vida, esto con base en Fals Borda (2010), mediante su validación inductiva-deductiva y los aportes interdisciplinarios generadores de nuevas ideas de conocimiento para preservar la tradición cultural en nuestra sociedad actual.

En ese contexto, se estableció una estrategia de diseño para la innovación social y la sostenibilidad, propuesta por el investigador Ezio Manzini (2015), al considerarla como la "capacidad para una actuación del diseño que busca hacer posible y probables estas nuevas maneras de ser y hacer las cosas" (p. 18). Es decir, el desarrollo de los sistemas (artefactos) plástico-sensoriales que atienden a las necesidades culturales, al inspirarse en los entornos naturales de la zona rural de El Encano, con menores oportunidades de material educativo regional, donde se valore y respete el conocimiento ancestral de su gente.

Se trató de entender la vida social y su dinámica para no dividirse como dos polos opuestos, sino para tratar de buscar esa unión en las diferentes formas de pensamiento colectivo, en virtud de la sabiduría del corazón ancestral de esos lugares naturales, que son afectados, transformados por el pensamiento moderno, el estudio índigo, la importancia de los entornos naturales, la vida y la cultura de los pueblos tradicionales e indígenas mediante sus saberes y prácticas simbólicas a partir del concepto de memoria biocultural (Toledo \& Barrera, 2008). ${ }^{1}$ Se trata de evocar esos objetos que transportan al pasado, los cuales reflejan la memoria de una cultura para ser evocada en la sociedad actual. 
Actualmente, la influencia moderna, en la sociedad del siglo XXI, ha perdido ese encantamiento que los unía con las culturas tradicionales transmitidas de los pueblos ancestrales precolombinos milenarios, al olvidar sus lugares de origen, el contacto con la naturaleza, los objetos simbólicos de memoria que representan la identidad de los habitantes del sur del Departamento de Nariño, su importancia en el saber pensar, saber sentir para crear, al adaptar nuevas formas de comunicación gráfica que, poco a poco, han provocado la pérdida del patrimonio. Es ahí donde el diseño se convierte en mediador educativo para preservar su simbología, para ser transmitida a las generaciones futuras, mediante prácticas creativas diversas e inspirando el diálogo cultural (Organización de las Naciones Unidas para la Educación, la Ciencia y la Cultura -UNESCO, 2001).

Por esto, el patrimonio biocultural y el conocimiento tradicional (UNESCO, 2016), se han convertido en un tema nacional e internacional para impulsar, dialogar y reflexionar. Constituye un problema interdisciplinar donde el diseño se preocupa a nivel regional para que estos conocimientos no se olviden dentro del territorio nariñense, al salvaguardar las manifestaciones del patrimonio biocultural de las comunidades indígenas tradicionales. Estas habitaron primero el territorio y concedieron esa herencia al transmitir los conocimientos arraigados a la tierra, al aprender, relacionarse y convivir con la naturaleza, las plantas y los animales; tradiciones que hoy se busca perdurar.

Por lo tanto, se llevó a cabo la investigación a través del diseño como mediador comunicacional entre los saberes ancestrales para ser transmitido a las nuevas generaciones con la acción participativa, tomando como caso de estudio la creatividad cultural infantil del grado quinto de la Institución Educativa Municipal de El Encano, sede El Puerto. En relación con el contexto de la laguna de La Cocha como lugar de memoria, se trabajó a partir de dos piezas del Museo del Oro del Banco de la República de Pasto: los colgantes en forma de patos y la nariguera en forma de media luna con dos garzas a sus lados, símbolos representativos del legado cultural Quillacinga de la serranía, en analogía con las aves acuáticas del contexto.

Al respecto se concibió la responsabilidad ética para visibilizar esos saberes ancestrales representados en símbolos patrimoniales, de modo que establezcan algunas manifestaciones en la coexistencia del hombre con la naturaleza dentro de un tiempo y un espacio, hacia el reconocimiento del territorio de vida. De ahí que la creatividad y la expresión simbólica asuman la responsabilidad de volver a las raíces culturales, debido a la forma de percibir, apreciar y pensar el mundo desde lo local (Noguera, 2017).

Al partir de una mirada de aprendizaje contextual cuyo pensamiento creativo evoca a los ancestros, en este sentido se comparó el saber indígena Quillacinga del pasado en relación con el presente como fuente de inspiración que impulsa a revelar ese conocimiento mediante la cosmovisión simbólica, comenzando con el pensamiento ético ambiental (Noguera, 2012; Escobar, 2016), desde una postura eurocéntrica. ${ }^{2}$ Rescatar la tradición indígena en armonía con la vida hace necesario que las nuevas generaciones se sientan orgullosas de su tierra, de sus raíces, puesto que serán las sociedades del mañana.

${ }^{1}$ La memoria biocultural propuesta por Víctor Toledo junto con Narciso Barrera-Bassols desde su teoría socioecológica, estudia el cambio histórico; de igual manera, los saberes y prácticas de los pueblos tradicionales e indígenas del mundo, la importancia para la vida y las relaciones complejas entre la naturaleza, el ser humano y la cultura. 
Por ese motivo, las piezas que se trabajaron son parte del patrimonio biocultural, y fortalecieron la investigación de manera puntual. Por consiguiente, se descodificó el saber ancestral, porque es ahí donde surgió la preocupación por la afectación de la vida natural a partir del desorden creado por el ser humano, para permitir una construcción más profunda, al darle forma en la estrategia de diseño para la innovación social en relación con los problemas de investigación: ¿Por qué es importante comprender el patrimonio biocultural, desde la expresión simbólica de los pueblos ancestrales? y ¿Cómo el diseño contribuye al reencantamiento con el patrimonio biocultural en la sociedad actual?

\section{Marco Teórico}

La UNESCO (2003) ha declarado el patrimonio cultural e inmaterial como una manifestación particular del conocimiento, en el uso respectivo con la naturaleza y el universo. Para Arévalo (2004): “El patrimonio remite a una realidad icónica (expresión material), simbólica (más allá de la cosificación y la objetualidad) y colectiva (expresión no particular, sino de la experiencia grupal)" (p. 930). En cambio, para el antropólogo y magíster en patrimonio cultural Johnny Ospina (2016): “Los objetos pueden convertirse en interés patrimonial si trasmiten una historia y no hay límites para ese espacio imaginativo” (p. 28).

Por lo tanto, el patrimonio biocultural se concibe como el proceso creativo experimental de un bien inmaterial que logra codificar los saberes ancestrales tradicionales mediante las representaciones simbólicas, identificando a una cultura dentro de una sociedad, reflejando su creatividad individual y colectiva adquirida por medio de la observación e interacción con la diversidad biológica y cultural. Puesto que se consideran fuentes de inspiración para crear espacios para el desarrollo pleno de la creatividad, se trae a colación la frase de Platón, quien planteó que las formas albergan el poder de crear todo aquello con lo que interactúa físicamente el hombre.

En este proceso, los símbolos codifican el conocimiento grupal de una memoria cognitiva del pasado, lo que Piaget (1981) llamó las relaciones construidas mediante una interacción continua entre el sujeto y el mundo exterior. Proceso neuronal donde el ojo observa y transmite al cerebro para que este piense, razone, extraiga y modifique los elementos naturales de un entorno para ser transformados en símbolos.

De tal manera que los símbolos configuran, distinguen e identifican el patrimonio de una cultura mediante sus representaciones, marcando su identidad y continuidad, su permanencia viva en el presente transmitido socialmente (Arévalo, 2004, p. 927). Junto con los valores y creencias de los antepasados y los actuales habitantes mayores, los símbolos

\footnotetext{
${ }^{2}$ La postura eurocéntrica considera a Europa y sus culturas como centro y motor de la civilización, para contar una historia universal desde las experiencias de observar el mundo histórico y cultural, mediante las normas y éticas que las caracterizan.
} 


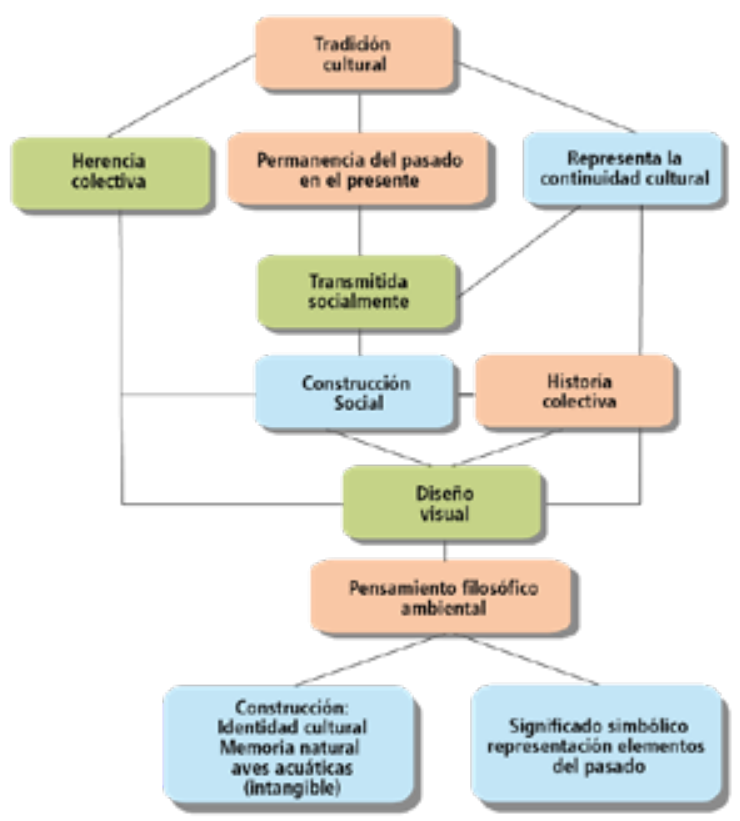

Figura 1. La tradición cultural es concepto integrativo, con la intención de darle significado al diseño visual. Adaptado de "La tradición, el patrimonio y la identidad” por J. Arévalo, 2004, p. 936.

El patrimonio se transmite de generación en generación. Al recrearlo constantemente con la comunidad o grupos en función del entorno, la interacción con la naturaleza y su historia, se une por el sentimiento de identidad y continuidad, contribuyendo así a promover el respeto por la diversidad biológica-cultural. El diseño se convierte, pues, en el promotor del reencantamiento. Al respecto, Maffesoli (2002) dice: "Volver a encantarnos en el sentido original de la palabra encantar; retomando la base social, o mejor dicho, una base popular" (p. 218).

Es fundamental que esta base social empiece a tomar conciencia de manera responsable. Esto implica "el post-desarrollo, el buen vivir, los derechos de la naturaleza, las lógicas comunales y las transición al post-extractivismo, como espacios importantes para profundizar el diseño para la transición" (Escobar, 2016, p.160). Para ello, el reencantamiento del mundo desde el pensamiento ambiental en Colombia, propuesto por Patricia Noguera (2012), quien plantea a las personas pensarse como participantes, moradores de barrio, ciudad, país, continente, planeta, universo, cambiando la forma de pensar la tierra, ya que "habitar sur, es habitar en la trama misma de la vida en su plenitud simbólico-biótica, no como dueños sino como hijos, como un hilo en la compleja trama de la vida" (p. 92).

Desde esta posición, se pensó el reencantamiento biocultural alrededor de un sentimiento de nostalgia de un pasado. En otras palabras, recordar lo que se había perdido y olvidado, generando ese acercamiento con la sociedad actual, puesto que respetar lo vivo implica una co-responsabilidad individual y colectiva hacia lo creado, lo mágico, lo divino. 
Se habla, entonces, de la pérdida del encantamiento cultural por parte de la sociedad, como una forma de interrelación con un enfoque biológico en el hábitat del contexto en la laguna de La Cocha. Es decir, las especies, aves acuáticas y la cultura en una memoria cognitiva tradicional a través de la intervención del diseño como lo define Noguera (2017): “El diseño como hilo conductor de posibilidades, al igual que la creatividad y expresión simbólica, asume la responsabilidad de volver a las raíces culturales; debido a la forma de percibir, apreciar y pensar el mundo desde lo local".

Para tal efecto la práctica del diseño, la importancia de los derechos humanos (Buchanan, 2001), en correlación con el diseño inspirado en la naturaleza, con la ciencia, el arte y la tecnología se unen conscientemente para la creación de diseños más eficaces. Para vivir mejor con la naturaleza, a través de una estrategia de innovación social (Manzini, 2015), se logra reencantar a una parte de la sociedad. Tal como lo manifiesta Macnab (2012):

El valor de diseño (...) conectado desde la memoria a través del ritual y el simbolismo, ofrece la experiencia estética del arte decorativo a los objetos utilitarios, brinda acceso a la información, a través de su rigor y organización nos ayuda a crear sistemas, herramientas con una función viable. (p. 64)

Esto implica la responsabilidad del diseño social en "el respeto por el saber tradicional y el papel de los seres humanos en la protección del medio ambiente, la biósfera y la biodiversidad" (UNESCO, 2005). En relación con el contexto actual asumiendo un nuevo reto mediante el diseño para la innovación social, se propuso estudiar la cultura infantil para crear diseños en función de la sociedad. Se tomó como modelo de gestión de desarrollo sostenible el del Programa de las Naciones Unidas para el Desarrollo (PNUD, 2016), específicamente el objetivo 15: "Medio ambiente: proteger, restaurar y promover el uso sostenible de los ecosistemas terrestres, el manejo sostenible de los bosques, la lucha contra la desertificación; detener, revertir la degradación de la tierra y detener la pérdida de biodiversidad" (p. 20).

Ahora bien, para lograr el reencantamiento biocultural en la sociedad actual, se planteó los siguientes componentes según las leyes y políticas nacionales e internacionales establecidas por la UNESCO, encargada de promover la educación, la ciencia y la cultura. Dichas políticas involucran los derechos de los pueblos indígenas a partir de los convenios internacionales, decretando la responsabilidad de la sociedad en general para la conservación del patrimonio, como se muestra en la tabla 1. 


\begin{tabular}{|c|c|}
\hline Derechos & Convenio legal UNESCO \\
\hline Patrimonio Cultural & Fuente de la Creatividad \\
\hline Salvaguardar & El Patrimonio Cultural Inmaterial. \\
\hline Educación, Ciencia y Cultura & Diversidad Cultural \\
\hline Responsabilidad Social & Bioética y Derechos Humanos \\
\hline Innovación Social & $\begin{array}{c}\text { Objetivo 15: Desarrollo } \\
\text { Sostenible (ODS) }\end{array}$ \\
\hline
\end{tabular}

Tabla 1. Normas y derechos establecidos por la UNESCO

Nota: datos obtenidos de las declaraciones, normas, derechos en el Programa de las Naciones Unidas para el Desarrollo (PNUD, 2001, 2003, 2005, 2015 - 2030).

Basado en lo anterior, el reencantamiento se manifiesta en los símbolos representativos de la herencia cultural de los "grupos humanos de carácter rural que no han sido transformados por los fenómenos de la modernización; por lo tanto, reflejan la herencia cultural en las formas antiguas y vigentes de la biodiversidad silvestre como doméstica" (Toledo \& Barrera, 2008, p. 40). Por lo tanto, las aves representan una pequeña parte de la biodiversidad, de gran valor para las creencias de los niños del grado quinto de la IEM de El Encano, sede El Puerto. Los alumnos se sintieron identificados cuando representaron gráficamente su territorio. El pensamiento filosófico ambiental se encuentra implícito en ellos, de tal forma que se ha transmitido de generación en generación creando un vínculo.

Respecto a lo anterior, Holly y Harry (2012) expresan que los pueblos indígenas y muchas comunidades locales tienen conexiones cercanas con los territorios y áreas específicas, ya que son los cimientos de sus identidades, culturas, idiomas y formas de vida. Es por ello que las actuales generaciones se consideran un legado del pueblo indígena Quillacinga de la serranía, preocupándose por defender, rescatar y conservar sus valores ancestrales, la armonía de lo sagrado, lo espiritual, la energía, el conocimiento, la sabiduría en la relación hombre-naturaleza-territorio como una hermandad que vela por sus derechos y creencias. A través de éstas, tienen conexión con sus antepasados, aprendieron de todas las formas de vida con las cuales coexistían, de tal forma que se debe seguir aprendiendo de ellas.

El diseño conecta la diversidad biológica y la cultura en un aprendizaje a través de la creatividad simbólica. Se trata de observar y pensar en el hábitat y todas las formas de vida con las cuales se convive. Se visibiliza un aprendizaje que pueda ser transmitido a las futuras generaciones para no perder este componente de la identidad nariñense. De ahí que los sujetos implicados se preocupen por seguir conservando y esparciendo el mensaje sobre la importancia de seguir aprendiendo de las culturas y el cuidado de la naturaleza, lo cual implica un compromiso de todos para proteger, restaurar y promover el respeto por la vida. Es por eso que el diseño se convirtió en ese hilo conductor que, a partir de los símbolos de las aves, configura una estrategia de innovación social y propone el reencantamiento biocultural en el diseño visto de esta forma. 


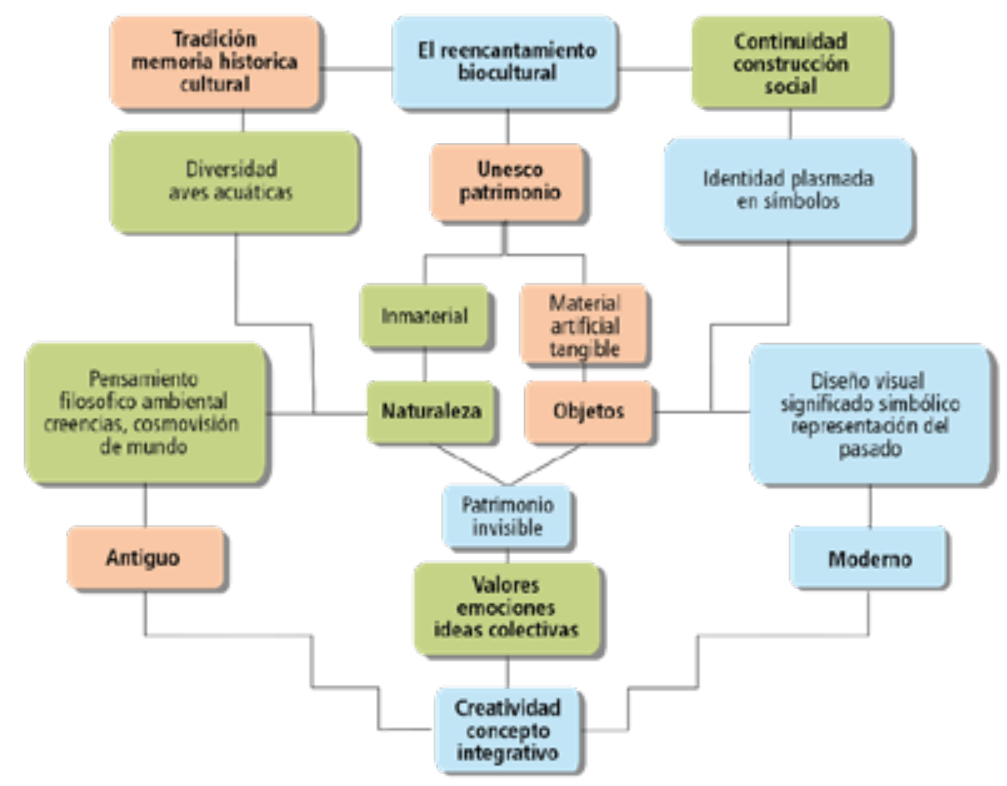

Figura 2. El reencantamiento biocultural en el diseño, vincula la tradición y la construcción social, al relacionar los elementos visuales de diseño en el patrimonio. Así se integra estos conceptos en el patrimonio, a través de la creatividad como concepto integrativo de diseño. Fuente: elaboración propia.

\section{Ruta Metodológica}

La estrategia de investigación a través del diseño para la innovación social, activa, mantiene y orienta los procesos de cambio social para la sostenibilidad (Manzini, 2015). En relación con el problema de investigación planteado, se eligió como estudio de caso, el grado quinto de la IEM de El Encano. Se aplicaron instrumentos cualitativos para la recopilación de la información, para reflexionar sobre la situación de ese fenómeno social. Al comparar rigurosamente la información, y unificada en el marco referencial teórico, el proceso de análisis/interpretación, de un grupo desde su mirada individual y cultural, facilitó las respuestas a las preguntas del por qué y el cómo, desde múltiples perspectivas (Banks, 2010).

Ese seguimiento se realizó con el método etnográfico y la investigación-acción participativa (IAP), como filosofía de vida al intervenir el caso de estudio. Igualmente, para la praxis del diseño, se retomaron las vivencias como una necesidad de participación y democracia, para comprender las actitudes y los valores como garantía de la verdad, y validando la información recolectada mediante el examen inductivo/deductivo. Esta búsqueda dio explicaciones apropiadas a partir de la realidad del contexto, al ser éste intervenido (Fals Borda,1998). En contraste con las técnicas de recolección de información y análisis, en este proceso de aprendizaje continuo, la investigadora observó, describió, analizó e interpretó.

Para ello se realizó una sesión de trabajo creativo, modelando la práctica participativamente, para crear ese espacio y compartir la información. De ahí que se implementó, también, el 
método etnografico, con el cual se examinó los comportamientos, costumbres y creencias aprendidas y compartidas del grupo, en complemento con el desarrollo de la actividad (praxis de campo), y emplear esta evidencia para la descripción (Guber, 2011; Angrosino, 2012).

Seguidamente, se procedió a registrar el trabajo de campo dentro del grupo Cultura infantil, mediante la observación participante individual/grupal. Con el fin de contrastar las técnicas de recolección de información, recopilación y revisión documental, se realizaron entrevistas semi-estructuradas, un taller de creación, preguntas del taller, se utilizó la antropología visual y el cruce de la información.

Finalmente, se fundamentó la investigación a través del diseño como estrategia de innovación social, en donde la teoría y la comprensión del mismo en el acto de diseñar, sirvió para generar conocimiento, al tener en cuenta que depende de la pureza técnica, significante en su trascendencia, para lograr un proceso de investigación propiamente dicho (Horta, 2012). Para la creación o rediseño del sistema o artefacto de diseño, se transmitió un conocimiento responsable, al promover el cuidado por el medio ambiente.

\section{Resultados y Discusión}

La estrategia de diseño para la innovación social unifica el concepto creativo (sentipensante) de sentir y actuar con el corazón, de Fals Borda (1999), en relación con la forma comunicacional. Para el diseño y desarrollo del material cultural educativo, se obtuvo como resultado el diseño co-responsable en el desarrollo del sistema, también llamado artefacto plástico-sensorial, a través de las narraciones digitales del cuento interactivo titulado: Una aventura en la Cocha. Este cuento fue co-diseñado con los dibujos creativos, siendo estos el resultado del taller creativo participativo con niños y para niños, pero también invita a adultos y jóvenes a volver a pensar en el territorio a través de los niños. Esta herramienta creativa reflexiona sobre la importancia del patrimonio biocultural, en el contexto rural de la laguna de La Cocha, para satisfacer las necesidades de aprendizaje cultural en función de la lectura.

La lectura generó esa armonía con los pueblos tradicionales para un cambio de comportamiento social no solo con las aves sino también con las culturas tradicionales, a través de la expresión gráfica, para ser plasmada en el patrimonio biocultural como parte integradora del universo. Esto implicó volver a aprender del saber ancestral y su relación de armonía con su entorno. Mediante las piezas museológicas de los Quillacingas del Museo del Oro de Pasto, se dio a conocer cómo esta cultura se inspiraba, aprendía y creaba con base en la representación gráfica de las aves, las cuales se visualizaban mediante la realidad aumentada (RA). Con el aplicativo móvil en un tiempo real les proporcionaba esta información aplicada en el software. Al escanear el código lector QR procesaba la información en los dispositivos tecnológicos móviles o en tablets, visibilizando la información para disfrutar de la experiencia (véase figura 3). 

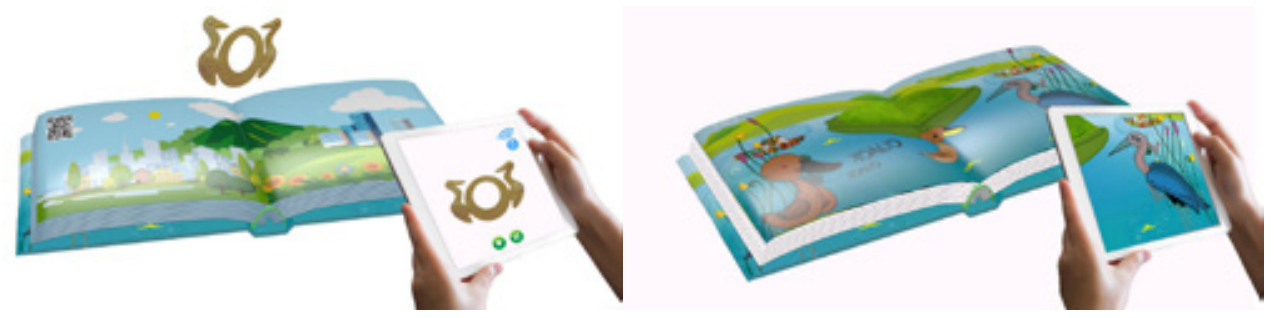

Figura 3. Mediante el escaneo del QR, con la tablet o el móvil, se accede a la información, en realidad aumentada y con los personajes del cuento interactivo, titulado: Una aventura en La Cocha.

Fuente: elaboración propia.

Enseguida invitaba a transportarse a la laguna de La Cocha. Las imágenes ilustradas para el cuento impreso análogo, en contraste con el software, imágenes, video, audio y modelado 3D, se convierten en la fuente para el aprendizaje social, el cual tiene ciertas carencias de productos culturales que promuevan el cuidado por la vida. Con el propósito de reencantar a los niños con la cultura del pasado en relación con la actual, se les presentaron cinco personajes: la garza azul, la patica pico amarillo, el pato colorado, el patico pico amarillo y Josefo, a quien le encantaba capturar las aves, contaminar el agua y talar los arboles. Estos personajes, en el contexto natural de La Cocha, se unificaban con el texto literario y con el estilo de personificación. En la metáfora se les otorga conceptos abstractos en relación con los valores culturales: amistad, respeto y amor, relacionándose con la sociedad actual al transmitir este conocimiento de generación en generación.

Al interactuar de manera individual y grupal generando esas experiencias sensibles con el sistema, junto con la tecnología mediante el uso del aplicativo móvil al escanear los códigos, se interactuaba con el audio, el sonido y la realidad aumentada. Esto conllevaba a estimular tres sentidos: la vista, el oído y el tacto, que generan reacciones emocionales de asombro, tristeza y alegría. Mediante su interacción se transmitió el conocimiento, generador de un cambio de comportamiento para el desarrollo sostenible, al crear conciencia en una sociedad sobre la valoración de la cultura, los territorios e invitar a apreciar y aprender de las representaciones culturales creativas. Así mismo, el volver a observar e inspirarse en la naturaleza, cuidar y respetar los recursos naturales como fuentes de información que representan, identifican e inspiran.

\section{Conclusiones}

Reconocer el patrimonio biocultural permitió prácticas responsables con la diversidad biológica y cultural para preservarlo de manera interdisciplinar, donde la ciencia, el arte y la tecnología se unificaron. Estas ideas creativas para el desarrollo de medios digitales, ya sean sistemas, artefactos, productos, servicios o modelos, aportan un vínculo social en armonía con el entorno para cuidar la región.

Los talleres creativos abrieron espacios de creación para el rescate de la memoria cultural del pasado a través de la creatividad simbólica en los niños y la transmisión de este mensaje a las generaciones futuras. 
La investigación-acción participativa, a través del diseño, plantea otras formas de hacer investigación al intervenir en diferentes problemáticas actuales. Esta búsqueda profunda de validación de la verdad práctico-teórica, para la producción-acción, le da ese valor a la red transmisora del conocimiento cultural para el beneficio social.

El cuento interactivo logró re-encantar a los niños al crear conciencia responsable, cultural y ambiental. Se modificaron sus comportamientos, sus prácticas se hicieron más conscientes con los entornos naturales y con la vida, forjando guardianes comprometidos con la tierra.

Las prácticas sociales de diseño permitieron darle seguimiento y continuación a esos procesos de diseño. Con los mismos casos de estudio, determinados en dos tiempos distintos, se evidenció que dichos sistemas, productos o artefactos generan reencantamiento en los niños, conocimientos perdurables, cambios de comportamiento, prácticas responsables y conscientes a través del tiempo.

Reconocer el patrimonio biocultural permite re-encantarse para preservarlo, siendo importante que tanto la zona rural y urbana se unan para aprender de todas las formas de vida que habitan estos lugares. Es por eso que el taller creativo abrió un espacio de creación, rescatando la memoria cultural del pasado a través de la creatividad simbólica en los niños y la transmisión de este mensaje a las generaciones futuras.

La investigación-acción participativa, a través del diseño, plantea otras formas de hacer investigación al intervenir en diferentes problemáticas actuales. Esta búsqueda profunda de validación de la verdad práctico-teórica, para la producción-acción, le da ese valor a la red trasmisora del conocimiento cultural para el beneficio social.

La praxis de diseño, junto con la teoría y la participación acción y co-creación, permitieron el desarrollo de nuevas estrategias para intervenir en el patrimonio biocultural, a través de estrategias de innovación social, logrando ese acercamiento social para su encantamiento. Igualmente, con el objetivo de dar respuesta a la pregunta de cómo una nueva iniciativa asiste a una cultura y la proyecta hacia el futuro, conectó la memoria histórica y cultural en relación con la actual, mediante sus saberes. Pensar, hacer y ser para empezar a valorar el diseño cultural en la educación como otra manera de transmitir el conocimiento en los establecimientos educativos.

\section{Referencias}

Angrosino, M. (2012). Etnografía y observación participante en la investigación cualitativa. Madrid: Ediciones Morata, S.L.

Arévalo, J. (septiembre-diciembre, 2004). La tradición, el patrimonio y la identidad. Revista de estudios extremeños, 60(3), 925-956.

Banks, M. (2010). Los datos visuales en la investigación cualitativa. Madrid: Ediciones Morata, S.L. 
Buchanan, R. (septiembre, 2001). Design research and the new learning. Design Issues, 17(3), 35-39. Recuperado de https: //proyectaryproducir.com.ar/public_html /Seminarios_ Posgrado/Material_de_referencia/Human\%20Digni

Escobar, A. (2016). Autonomía de diseño. La realización de lo comunal. Popayán: Universidad del Cauca.

Fals Borda, O. (2010) Antología Orlando Fals Borda. Bogotá, DC.: Universidad Nacional de Colombia.

Guber, R. (2011). La etnografía: método, campo y reflexividad. Buenos Aires: Siglo XXI Editores. Horta, A. (2012). Trazos poéticos del diseño. Manizales: Editorial Universidad de Caldas.

Macnab, M. (2012). Diseño inspirado en la naturaleza. Madrid: Ediciones Anaya Multimedia.

Maffesoli, M. (enero-abril, 2002). El reencantamiento del mundo. Sociológica, 17(48), 213-241.

Manzini, E. (2015). Cuando todos diseñan. Una introducción al diseño para la innovación social. Madrid: Experimenta.

Manzini, E. (2015). Design, when everybody designs: An Introduction to Design for social Innovation. Massachusetts, USA: The Mit Press.

Noguera, A. P. (2012). El enigma, el habitar, la vida: emergencias de un pensamiento ambiental en clave del reencantamiento del mundo. Madrid: Editorial Académica Española.

Noguera, P. (14 de noviembre de 2017). Comunicación personal para H. Y. Zamudio Ceballos [Soporte físico]. Pasto.

Ospina, J. M. (2016). Patrimonio cultural: ¿espacio de imaginación o de especulación? En C. Carreño, J. Ospina, M.Mora, K.Ochoa \& L. Rodríguez (Eds.), Cuadernos de Patrimonio Cultural. Reflexiones Contemporáneas (pp. 27-42). Tunja: Universidad Pedagógica y Tecnológica de Colombia.

Piaget, J. (1981). La teoría de Piaget. Journal for the Study of Education and Development, 4(2), 13-54.

Programa de las Naciones Unidas para el Desarrollo (PNUD). (2016). Ods Colombia: herramienta de aproximación al contexto local. Recuperado de http://blogpedagogiadialogante.com/ docs/capitulojdz_ods_colombia.pdf

Toledo, V. M. \& Barrera, N. (2008). La memoria biocultural. La importancia ecológica de las sabidurías tradicionales. Barcelona: Icaria Editorial.

Organización de las Naciones Unidas para la Educación, la Ciencia y la Cultura (UNESCO). (2001). Declaración universal de la Unesco sobre la diversidad cultural. Recuperado de http: //portal.unesco.org/es/ev.phpURL_ID=13179\&URL_DO=DO_TOPIC\&URL_ SECTION=201.html

Organización de las Naciones Unidas para la Educación, la Ciencia y la Cultura (UNESCO). (2003). Convención para salvaguardia del patrimonio cultural inmaterial. Recuperado de 2017, en http://unesdoc.unesco.org/images/0013/001325/132540s.pdf

Organización de las Naciones Unidas para la Educación, la Ciencia y la Cultura (UNESCO). (2005). Declaración Universal sobre Bioética y Derechos Humanos. Recuperado de http://portal. unesco.org/es/ev.phpURL_ID=31058\&URL_DO=DO_TOPIC\&URL_SECTION=201.html

Organización de las Naciones Unidas para la Educación, la Ciencia y la Cultura (UNESCO). (2016). Simposio sobre Patrimonio Biocultural. Diálogo de Saberes y Políticas Públicas en México. Recuperado de 2018, en http://www.unesco.org/new/es/media-services/ singleview/news/simposio_sobre_patrimonio_biocultural_dialogo_de_saberes_y 